\title{
Activation of toll-like receptors 2, 3, and 4 on human melanoma cells induces inflammatory factors
}

\author{
Yasufumi Goto, ${ }^{1}$ Takaaki Arigami, ${ }^{1}$ \\ Minoru Kitago, ${ }^{1}$ Sandy L. Nguyen, ${ }^{1}$ \\ Norihiko Narita, ${ }^{1}$ Soldano Ferrone, ${ }^{2}$ \\ Donald L. Morton, ${ }^{3}$ Reiko F. Irie, ${ }^{4}$ \\ and Dave S.B. Hoon ${ }^{1}$
}

\begin{abstract}
${ }^{1}$ Department of Molecular Oncology, John Wayne Cancer Institute, Santa Monica, California; ${ }^{2}$ University of Pittsburgh Cancer Institute, Departments of Surgery, Immunology, and Pathology, Pittsburgh, Pennsylvania; ${ }^{3}$ Division of Surgical Oncology and ${ }^{4}$ Department of Biotechnology, John Wayne Cancer Institute, Santa Monica, California
\end{abstract}

\begin{abstract}
Toll-like receptors (TLR) have been shown to be expressed on various types of cancers; however, their functional activity is not known. We examined TLR profiles of human melanoma cells and showed that TLR2, TLR3, and TLR4 were found to be highly expressed. By PCR array analysis, specific stimulation of TLR2, TLR3, and TLR4 on melanoma cells showed significant activation of the adaptor protein MyD88, as well as downstream signal transduction factors nuclear factor $\kappa B$ and inflammatory response-related factors. Specific ligand activation of TLR2, TLR3, and TLR4 was shown to induce cell migration. Peripheral blood lymphocytes and melanoma purified RNA was shown to activate TLR3 on melanoma cells. These studies show expression and functional activity of specific TLRs on melanoma cells and as potential therapeutic targets to control tumor progression. [Mol Cancer Ther 2008;7(11):3642-53]
\end{abstract}

\section{Introduction}

Toll-like receptors (TLR), the mammalian homologues of the Drosophila Toll protein, play a critical role in inflammation and innate and adaptive immunity to many human diseases $(1,2)$. In infectious disease, TLR on host monocytes recognize pathogen-associated molecular patterns $(3,4)$;

Received 1/31/08; revised 6/20/08; accepted 7/9/08

Grant support: NIH National Cancer Institute Project II PO CA029605 and CA012582 grants and R01CA105500.

The costs of publication of this article were defrayed in part by the payment of page charges. This article must therefore be hereby marked advertisement in accordance with 18 U.S.C. Section 1734 solely to indicate this fact.

Requests for reprints: Dave S.B. Hoon, Department of Molecular Oncology, John Wayne Cancer Institute, 2200 Santa Monica Boulevard, Santa Monica, CA 90404. Phone: 310-449-5267; Fax: 310-449-5282. E-mail: hoon@jwci.org

Copyright (C) 2008 American Association for Cancer Research.

doi:10.1158/1535-7163.MCT-08-0582 this recognition stimulates monocyte expression of proinflammatory cytokines and costimulatory molecules that link the early (innate) response to the subsequent development of specific immunity. TLR on immune cells have been implicated in adaptive immune responses; studies have examined several TLR-based therapeutic approaches to increase the efficacy of anticancer immunotherapies. Recently, there has been evidence that TLR are expressed on some types of human cancer cells (5-8). Studies have reported that human melanoma cells express TLR3 and TLR4 on the cell membrane $(5,8)$. However, the expression of TLRs of melanoma cells in vivo and their functional activity is not known in human cutaneous melanoma.

TLR-activated innate immunity in the skin during injury or infection has been linked to inflammation (9). Inflammatory responses are known to increase the risk for the development and promotion of cancer (10-13). Primary melanoma tumors often contain tumor-infiltrating hematopoietic cells that are characteristic of innate immune response $(12,13)$. The study objective was to determine if TLR are present on melanoma cells in vitro and in vivo and if they could be activated. Because inflammation is observed in cutaneous primary melanomas during tumor progression, our primary hypothesis was that melanoma cells express functional TLR, which, upon activation, initiate proinflammatory signal transduction-related pathways, similar to immune cells. These events may be instrumental in fostering a tumor microenvironment supportive of tumor progression. Bioactive factors activated in melanoma cells in response to TLR activation may play a significant role in dampening antitumor immunity.

To our knowledge, this is the first report profiling the expression of TLR on human cutaneous melanoma cells and tumor cells in vivo, and also that these TLRs, when activated, can induce signal transduction pathways with similar patterns to TLR-bearing leukocytes. Our findings support a link between TLR expression and activation by melanoma cells and inflammatory factor release, suggesting a phenotype supportive of melanoma progression. TLR and respective signaling pathways on melanoma cells may be potential therapeutic targets to control tumor progression.

\section{Materials and Methods \\ Cell Lines}

Fifteen established human metastatic melanoma cell lines (ME1, ME2, ME5, ME7, ME8, ME9, ME10, ME16, ME17, ME18, ME19, ME20, ME21, ME22, and ME23) were studied. Controls included human cell lines established from colon cancer (SW480), pancreatic cancer (PANC-1), 
umbilical vein endothelial cells (HUVEC), peripheral blood lymphocytes (PBL) from healthy donors (PBL-A, PBL-B, PBL-1, PBL-2, PBL-3, PBL-4, PBL-5, PBL-6, PBL-A1, PBL-A2, PBL-A3, and PBL-A4), and cultured primary neonatal melanocytes (HEnM-MP, Cascade Biologics). Informed consent for use of all human specimens in this study was obtained under a protocol approved by Saint John's Health Center/John Wayne Cancer Institute institutional review board. All cell lines, except PANC-1 and melanocytes, were grown in Life Technologies RPMI 1640 (Invitrogen) supplemented with 10\% heat-inactivated fetal bovine serum (FBS). PANC-1 was grown in DMEM with $10 \%$ heat-inactivated FBS, and melanocytes were grown in Medium 254 (Cascade Biologics) containing human melanocyte growth supplement (Cascade Biologics). All cell lines were cultured at $37^{\circ} \mathrm{C}$ in a humidified atmosphere containing $5 \% \mathrm{CO}_{2}$, as previously described (14).

\section{Flow Cytometry}

Flow cytometry analyses were done on BD FACSCalibur System (BD Biosciences) using standard techniques. For each analysis, $1 \times 10^{6}$ cells were stained with $3 \mu \mathrm{g}$ of a monoclonal antibody specific to TLR2-PE or TLR4-PE (IMGENEX) at the cell surface, and TLR3-PE (IMGENEX) at the cell surface or intracellularly or early endosome antigen 1-FITC (BD Biosciences). PE-conjugated mouse IgG1, IgG2a, and FITC-conjugated mouse IgG1 (BD Biosciences) for each monoclonal antibody were used as isotype controls. Cells were fixed in $4 \%$ formaldehyde and incubated for $30 \mathrm{~min}$ at $4{ }^{\circ} \mathrm{C}$ with direct conjugated monoclonal antibodies. To block nonspecific binding, PBS (pH 7.4; Invitrogen) supplemented with 1\% FCS was used for all labeling and washing steps. All flow cytometry data were analyzed using Cellquest software (Becton Dickinson).

\section{Fluorescence Microscopy}

Cells were fixed with $4 \%$ paraformaldehyde in PBS for $10 \mathrm{~min}$ and then incubated inside a $37^{\circ} \mathrm{C}$ humidified atmosphere containing $5 \% \mathrm{CO}_{2}$ for $20 \mathrm{~min}$, during which time, the cells were maintained in RPMI 1640 supplemented with $10 \%$ FBS and $20 \mu \mathrm{g} / \mathrm{mL}$ of FITC-lipopolysaccharide (LPS; Sigma). To stain cell nuclei, sections were incubated with 4',6-diamidino-2-phenylindole (Vector Laboratories, Inc.), as described by the manufacturer's protocol. After washing, cells were visualized using a Nikon Eclipse $\mathrm{Ti}$ fluorescence microscope (Nikon Instruments, Inc.) fluorescence microscope.

\section{RNA Isolation, Primers, and Probes}

Total RNA was extracted from cells using Tri-Reagent (Molecular Research Center, Inc.), as previously described $(15,16)$. RNA extraction procedures were done in a designated sterile laminar flow hood with RNase-free labware. Isolated RNA was quantified and assessed for quality and purity by UV spectrophotometry and RIBOGreen detection assay (Molecular Probes), as previously described (17). RNA extraction, reverse transcription-PCR (RT-PCR) assay set up, and post-RT-PCR product analysis were carried out in separate rooms to prevent crosscontamination (18).
Primer and probe sequences (see Supplementary Table S1) ${ }^{5}$ for 10 TLRs, 5 melanoma markers, and TLR adaptor proteins were designed for RT-PCR and quantitative RT-PCR (qRT-PCR), as previously described (19). Each specific gene primer set amplified at least one exon-intronexon region, such that the probe covered two exons. Initially, all RT-PCR products were assessed by gel electrophoresis to confirm the amplicon size and visually assess the product specificity.

\section{RT-PCR}

Reverse-transcriptase reactions were done on $1.0 \mu \mathrm{g}$ of extracted total RNA using Moloney murine leukemia virus reverse-transcriptase (Promega) with oligo-dT primers, as previously described (19). The PCR assay for each TLR began with one cycle of denaturation at $95^{\circ} \mathrm{C}$ for $5 \mathrm{~min}$, followed by 30 cycles of $95^{\circ} \mathrm{C}$ for $1 \mathrm{~min}, 1-\mathrm{min}$ annealing period of $60^{\circ} \mathrm{C}$ for TLR1, TLR3, TLR5, TLR7, TLR8, TLR9, and TLR10; $63^{\circ} \mathrm{C}$ for TLR2 and TLR6; $54^{\circ} \mathrm{C}$ for TLR4; and $55^{\circ} \mathrm{C}$ for glyceraldehyde-3-phosphate dehydrogenase (GAPDH). A second 1-min annealing period was completed at $72^{\circ} \mathrm{C}$ before a final extension at $72^{\circ} \mathrm{C}$ for $10 \mathrm{~min}$.

RT-PCR assessment of five cell surface markers was used to monitor the purity of melanoma cells isolated from tumor biopsy specimens. Samples were amplified with a precycling hold at $95^{\circ} \mathrm{C}$ for $5 \mathrm{~min}$, followed by 35 cycles of annealing/extension for $1 \mathrm{~min}$ (at $56^{\circ} \mathrm{C}$ for cytokeratin 20 , at $59^{\circ} \mathrm{C}$ for melanoma antigen recognized by $\mathrm{T}$ cells (MART-1), at $62^{\circ} \mathrm{C}$ for CD3 $\gamma$, at $63^{\circ} \mathrm{C}$ for CD45 and CD34, and at $55^{\circ} \mathrm{C}$ for GAPDH), 1 minute of extension at $72^{\circ} \mathrm{C}$, and $10 \mathrm{~min}$ of final extension at $72^{\circ} \mathrm{C}$. The specificity of PCR conditions and annealing temperatures for each marker were optimized using an Omni thermocycler (Hybaid). The RT-PCR cDNA products were verified using a $2 \%$ agarose gel.

The qRT-PCR assay was done on the iCycler iQ RealTime PCR Detection System (Bio-Rad Laboratories) using $250 \mathrm{ng}$ of total RNA for each reaction, as previously described (20). The PCR reaction mixture consisted of specific primers, TaqMan probe, 1 unit of AmpliTaq Gold polymerase (Applied Biosystems), $200 \mu \mathrm{mol} / \mathrm{L}$ each of deoxynucleotide triphosphate, $4.5 \mathrm{mmol} / \mathrm{L} \mathrm{MgCl}_{2}$, and AmpliTaq buffer diluted to a final volume of $25 \mu \mathrm{L}$. Samples were amplified with a precycling hold at $95^{\circ} \mathrm{C}$ for $10 \mathrm{~min}$, followed by 35 cycles of denaturation at $95^{\circ} \mathrm{C}$ for $1 \mathrm{~min}$, annealing for $1 \mathrm{~min}$ at $55^{\circ} \mathrm{C}$ for GAPDH, $63^{\circ} \mathrm{C}$ for TLR2, $60^{\circ} \mathrm{C}$ for TLR3, $54^{\circ} \mathrm{C}$ for TLR4, $60^{\circ} \mathrm{C}$ for MyD88, and $60^{\circ} \mathrm{C}$ for TRIF, and extension at $72^{\circ} \mathrm{C}$ for $1 \mathrm{~min}$. Each sample was assayed in triplicate with positive and reagent controls. Absolute copy numbers were determined by a standard curve with serial dilutions $\left(10^{6}-10^{1}\right.$ copies) of DNA containing TLR2, TLR3, and TLR4 cDNA templates. TLR2, TLR3, and TLR4 expression were given as a ratio of TLR2, TLR3, or TLR4/ GAPDH copy numbers.

\footnotetext{
${ }^{5}$ Supplementary material for this article is available at Molecular Cancer Therapeutics Online (http://mct.aacrjournals.org/).
} 


\section{PCR Array}

The relative mRNA expressions of TLR, adaptors and effectors of TLR, and other genes related to TLR-mediated signal transduction were analyzed with a human TLR signaling pathway Gene Array (GEArray Q Series, SuperArray, Inc.) according to the manufacturer's protocol. This analysis used cDNA obtained from melanoma cell lines ME2 and ME5 before and after cells were stimulated with ligands for TLR2 (zymosan, InVivoGen), TLR3 [polyIMP/ poly-CMP] (PIC), BD Biosciences], or TLR4 (LPS, Lippopolysacchnide, from Escherichia coli serotype 0111:4B, Sigma-Aldrich). PIC showed no endotoxin contamination $(<0.2 \mathrm{ng} / \mathrm{mL}$ as determined with the Limulus test). Melanoma cells $\left(5 \times 10^{5}\right)$ were placed in RPMI 1640 supplemented with $2.5 \%$ heat-inactivated FBS and either LPS $(1 \mu \mathrm{g} / \mathrm{mL})$, PIC $(100 \mu \mathrm{g} / \mathrm{mL})$, zymosan $(10 \mu \mathrm{g} / \mathrm{mL})$, or no ligand (negative control). Cells with ligand were incubated at $37^{\circ} \mathrm{C}$ in a humidified atmosphere containing $5 \% \mathrm{CO}_{2}$; the duration of incubation was $4 \mathrm{~h}$ with LPS, $24 \mathrm{~h}$ with PIC, and $18 \mathrm{~h}$ with zymosan. After incubation, cells were washed with PBS, total RNA was extracted, and RT-PCR was done as described above. Briefly, the PCR array was done on the iCycler iQ RealTime PCR Detection System using $10 \mathrm{ng}$ of total RNA and PCR master mix for SYBR Green detection for each reaction $(2,21)$. Samples were amplified with a precycling hold at $95^{\circ} \mathrm{C}$ for $10 \mathrm{~min}$ and then followed by 40 cycles of denaturation at $95^{\circ} \mathrm{C}$ for $15 \mathrm{~s}$ and annealing for $1 \mathrm{~min}$ at $60^{\circ} \mathrm{C}$.

\section{Isolation of Melanoma Cells from Tumor Biopsies}

Fresh tissue was minced under sterile conditions at $4^{\circ} \mathrm{C}$. The cell suspension was agitated in RPMI 1640 and filtered first through sterile gauze and then through sterile stainless mesh. After washing by centrifugation, cells were program-frozen at $1^{\circ} \mathrm{C} / \mathrm{min}$ in fluid containing RPMI 1640 with 20\% $\gamma$-globulin-depleted human serum, penicillin, streptomycin, fungizone, and 10\% DMSO and stored in a liquid nitrogen freezer. On the day of analysis, the cells were thawed rapidly at $37^{\circ} \mathrm{C}$, washed with PBS, and incubated for $20 \mathrm{~min}$ at $4^{\circ} \mathrm{C}$ in magnetic beads (Dynabeads Cellection Pan Mouse IgG kit, Invitrogen) that had been washed and precoated with a cocktail of monoclonal antibodies to high-molecular weightmelanoma-associated antigens, a cell surface antigen, by a 30 -min incubation of $1 \times 10^{7}$ beads with $2 \mu \mathrm{g}$ of high-molecular weight-melanoma-associated antigen monoclonal antibody at $4{ }^{\circ} \mathrm{C}(22)$. Bead-bound melanoma cells were then isolated using a magnet and separated from the beads by incubation in releasing buffer (DNase I, Invitrogen) for $15 \mathrm{~min}$ at room temperature, followed by magnetic separation as described by the manufacturer. Isolation of melanoma cells was confirmed by light microscopic examination of stained cells using a Leica DM LB phase-contrast light microscope (14). Total RNA was extracted from isolated melanoma cells, as described above.

\section{Cell Migration}

Melanoma cells were harvested from culture dishes using trypsin-EDTA and washed twice with PBS. Cells $\left(5 \times 10^{4}\right)$ were resuspended in $2.5 \%$ FBS RPMI and seeded into the $8.0-\mu \mathrm{m}$ pore polycarbonate membrane insert of a 6.5-mm Transwell (Corning, Inc.; ref. 14). The lower Transwell chamber was filled with $2.5 \%$ FBS RPMI containing LPS $(10 \mu \mathrm{g} / \mathrm{mL})$, PIC $(1000 \mu \mathrm{g} / \mathrm{mL})$, zymosan $(100 \mu \mathrm{g} / \mathrm{mL})$, or no ligand (negative control). After incubation at $37^{\circ} \mathrm{C}$ for $24 \mathrm{~h}$ in a humidified atmosphere with $5 \% \mathrm{CO}_{2}$, the Transwell chambers were removed, and cells that had migrated to the lower chamber were incubated for an additional $6 \mathrm{~h}$ at $37^{\circ} \mathrm{C}$. These cells were then fixed in $80 \%$ ethanol, washed with PBS, and stained with H\&E. Two reviewers (Y. G., A. T.) independently counted the number of migrated cells in 10 different fields at $200 \times$ magnification with a light microscope, as described above.

Treatment of Melanoma Cells with PBLs Supernatant

PBLs $\left(5 \times 10^{5}\right)$ from four normal donor volunteers were cultured with RPMI 1640 supplemented with 5\% heat-inactivated human antibody serum (5\% HABS RPMI; Mediatech, Inc.), with and without $20 \mu \mathrm{g} / \mathrm{mL}$ leucoagglutinin (PHA-L, Sigma-Aldrich) for $72 \mathrm{~h}$. The supernatants of the cultured PBLs were then collected. Melanoma cells $\left(6 \times 10^{5}\right)$ were incubated with $2.5 \mathrm{~mL}$ of $10 \%$ FBS RPMI, in addition to either $2.5 \mathrm{~mL}$ of the supernatant containing PHA-L, $2.5 \mathrm{~mL}$ of the supernatant lacking PHA-L, or $2.5 \mathrm{~mL}$ of plain 5\% HABS RPMI containing $20 \mu \mathrm{g} / \mathrm{mL}$ PHA-L (control culture medium) for $72 \mathrm{~h}$. After incubation, melanoma cells were washed with PBS and total RNA was extracted as described above. PHA-L-stimulated lymphocyte RNA was extracted and purified extensively, quantified, and used for stimulation experiments.

PBLs $\left(3 \times 10^{6}\right)$ from four normal donor volunteers were cultured with RPMI 1640 supplemented with 5\% HABS RPMI with $20 \mu \mathrm{g} / \mathrm{mL}$ PHA-L (Sigma) for $48 \mathrm{~h}$, and PBLs were harvested. RNA was extracted from PBLs and ME1 as described above. Then, $6 \times 10^{5}$ melanoma cells (ME1 and ME5) were incubated in RPMI 1640 alone or with $50-\mu \mathrm{g}$ purified RNA from PHA-L-stimulated PBLs or ME-1 for $2 \mathrm{~h}$. Melanoma cells were cultured with culture medium for $70 \mathrm{~h}$. After incubation, total RNA was extracted for stimulation of melanoma cells as described above.

\section{Statistical Analysis}

The Student's $t$ test was used to analyze the number of cells that migrated in response to stimulation with TLR ligands or no ligands. ANOVA was used to compare TLR2, TLR3, TLR4, and MyD88 expression in melanoma cells cultured with PHA-L-stimulated PBL supernatant compared with nonstimulated PBL supernatant. Means and $95 \%$ confidence intervals were calculated based on the log-transformed data and then transformed back to the original scale. Differences between means were also calculated based on the log-transformed data and then transformed back to the original scale to get the fold increase between different media. Analysis was done using SAS statistical software (SAS Institute), and all tests were two-sided with a significance level of $P<0.05$. 


\section{Results}

\section{TLR Expression by Melanoma Lines}

Six established metastatic melanoma cell lines (ME2, ME5, ME9, ME16, ME17, and ME-19) were initially prescreened by RT-PCR and gel electrophoresis for the expression of TLR1 to TLR10. The TLR expression profile of the melanoma lines is shown in Fig. 1A. All melanoma lines expressed more than two TLR. TLR2, TLR3, and TLR4 were strongly expressed on all melanoma lines, with one exception. TLR6 was strongly expressed on only one line, and TLR1, TLR5, TLR6, TLR7, TLR8, TLR9, and TLR10 were either absent or weakly expressed on melanoma lines. We therefore focused our subsequent studies on TLR2, TLR3, and TLR4.

We then used a sensitive qRT-PCR assay to quantify the expression of TLR2, TLR3, and TLR4 in 13 established human melanoma lines and a human melanocyte line. PBLs were used as positive controls, and PANC1 [TLR2(-), TLR3(-), TLR4(-)] was used as a negative control. All qRT-PCR assays were normalized by GAPDH copy numbers, as previously described (18-20). The range of absolute mRNA copies was 0 to $1.9 \times 10^{3}$ for TLR2, $5.0 \times 10^{1}$ to $1.1 \times 10^{3}$ for TLR3, 0 to $6.7 \times 10^{3}$ for TLR4, and $6.9 \times 10^{6}$ to $7.1 \times 10^{7}$ for GAPDH. The range of mRNA copy ratios (TLRs/GAPDH) was $1.2 \times 10^{-6}$ to $1.4 \times 10^{-4}$ for TLR2/GAPDH, $3.5 \times 10^{-6}$ to $9.1 \times 10^{-5}$ for TLR3/GAPDH, and $2.2 \times 10^{-6}$ to $2.7 \times 10^{-4}$ for TLR4/ GAPDH. The results of TLR profile expression by qRTPCR are shown in Fig. 1B. TLR2 was expressed by 8 of the 13 melanoma lines tested; TLR3 and TLR4 were expressed in all the melanoma lines, except that TLR3 was not detected in ME21 cells. Interestingly, TLR2, TLR3, and TLR4 expression were detected in normal primary melanocyte cell cultures.

TLR Fluorescence-Activated Cell Sorting Analysis of Melanoma Lines

Representative fluorescence-activated cell sorting analysis showed TLR2, TLR3, and TLR4 expression on the cell surface of melanoma lines ME2 and ME5 (Fig. 1C). This analysis showed that the protein expression levels correlated with mRNA expression levels of TLR2, TLR3, and TLR4 on melanoma cells, as shown in Fig. 1B.

We further used FITC-LPS to investigate whether TLR4 can bind LPS on the cell membrane surface of six human melanoma cell lines. Other ligands binding with FITC were not available. All the six melanoma cell lines were stained with FITC-LPS and 4',6-diamidino-2-phenylindole (Fig. 1D). This showed direct binding of LPS to melanoma cells and confirms that LPS is a ligand of TLR4.

Expression of TLR on Melanoma Cells from Tumor Specimens

Assessment of melanoma tumor specimens for TLR expression is difficult, because melanoma lesions are often infiltrated by a significant number of hematopoietic cells and endothelial cells that express TLRs. Therefore, we used a magnetic bead based technique to isolate melanoma cells from single-cell suspensions obtained from melanoma tumor biopsies. RT-PCR analysis for MART-1 (melanoma marker), CD45 (leukocyte-common antigen), CD3- $\gamma$ (T-cell antigen receptor complex), cytokeratin 20 (endothelial antigen), and CD34 (hematopoietic progenitor cell antigen) was used to assess the purity of the isolated melanoma cell populations (Fig. 2A). TLR2, TLR3, and TLR4 mRNA expression in purified melanoma cells was then assessed by qRT-PCR. These studies corroborated the analysis of TLR2, TLR3, and TLR4 mRNA expression in established melanoma lines (Fig. 2B). TLR3 and TLR4 were expressed in all nine samples of purified melanoma biopsy cells; TLR2 was expressed in eight of the nine biopsy specimens. The average mRNA copy numbers of TLR2, TLR3, and TLR4 expressed in purified melanoma cells matched those in melanoma biopsy cell lines. These findings validated the in vivo and in vitro expression patterns of TLR2, TLR3, and TLR4 in melanoma cells and that TLR expression by melanoma cells was not an in vitro artifact. The difference between fluorescence-activated cell sorting and qRT-PCR analysis is likely reflected by assay sensitivity. The latter will be dependent on specific antibody recognition of epitopes, as well as posttranslational processing before cell surface expression.

\section{PCR Array Analysis of TLR-Activated Genes}

To determine if activation of TLRs by melanoma cells induced the expression of proinflammatory cytokines, we analyzed the expression of genes related to TLR-mediated signal transduction and inflammatory cytokines in melanoma lines before and after specific ligand stimulation by quantitative PCR array. Distinctive TLR activation of downstream genes in melanoma is shown in the gene expression heat map (Fig. 3). As shown in Table 1, stimulation of cells with LPS, PIC, or zymosan induced more than a $4 \times$ increase in expression of TLR2, TLR3, TLR4, and their adaptors and effector molecules, respectively. Notably, the expression of MyD88 increased $>8 \times$. To verify this increase by a more quantitative assay, we did qRT-PCR on ligand-activated melanoma cells: MyD88 expression increased $5.7 \times, 6.3 \times$, and $4.4 \times$ in ME2 cells and $9.1 \times, 5.0 \times$, and $10.5 \times$ in ME5 cells after stimulation with specific ligands for TLR2, TLR3, and TLR4, respectively (Fig. 4). PCR array analysis also showed significant mRNA expression up-regulation of nuclear factor- $\kappa \mathrm{B}(\mathrm{NF}-\kappa \mathrm{B})$ and IRF genes, which are activated by MyD88 (23). NF- $\kappa$ B1 was elevated $>8 \times, 4 \times$, and $2 \times$ after stimulation with LPS, PIC, and zymosan, respectively. NF-kB2 was also elevated $>2 \times$ after stimulation with either PIC or zymosan. IRF1 increased $>4 \times, 2 \times$, and $4 \times$ after stimulation with LPS, PIC, and zymosan, respectively. IRF3 expression was elevated $>8 \times$ and $2 \times$ after stimulation with LPS and zymosan, respectively. Interestingly, CD14, a known complex associated with TLR4 and involved in LPS recognition, was detected and elevated after stimulation with all the individual TLR ligands assessed.

We analyzed the expression of Toll-IL-1 receptor domaincontaining adaptor inducing interferon (TRIF) in melanoma lines before and after specific ligand stimulation by qRTPCR and, also, expression of MyD88 in parallel. Expression of TRIF was induced in stimulated cells with LPS, PIC, or 
A
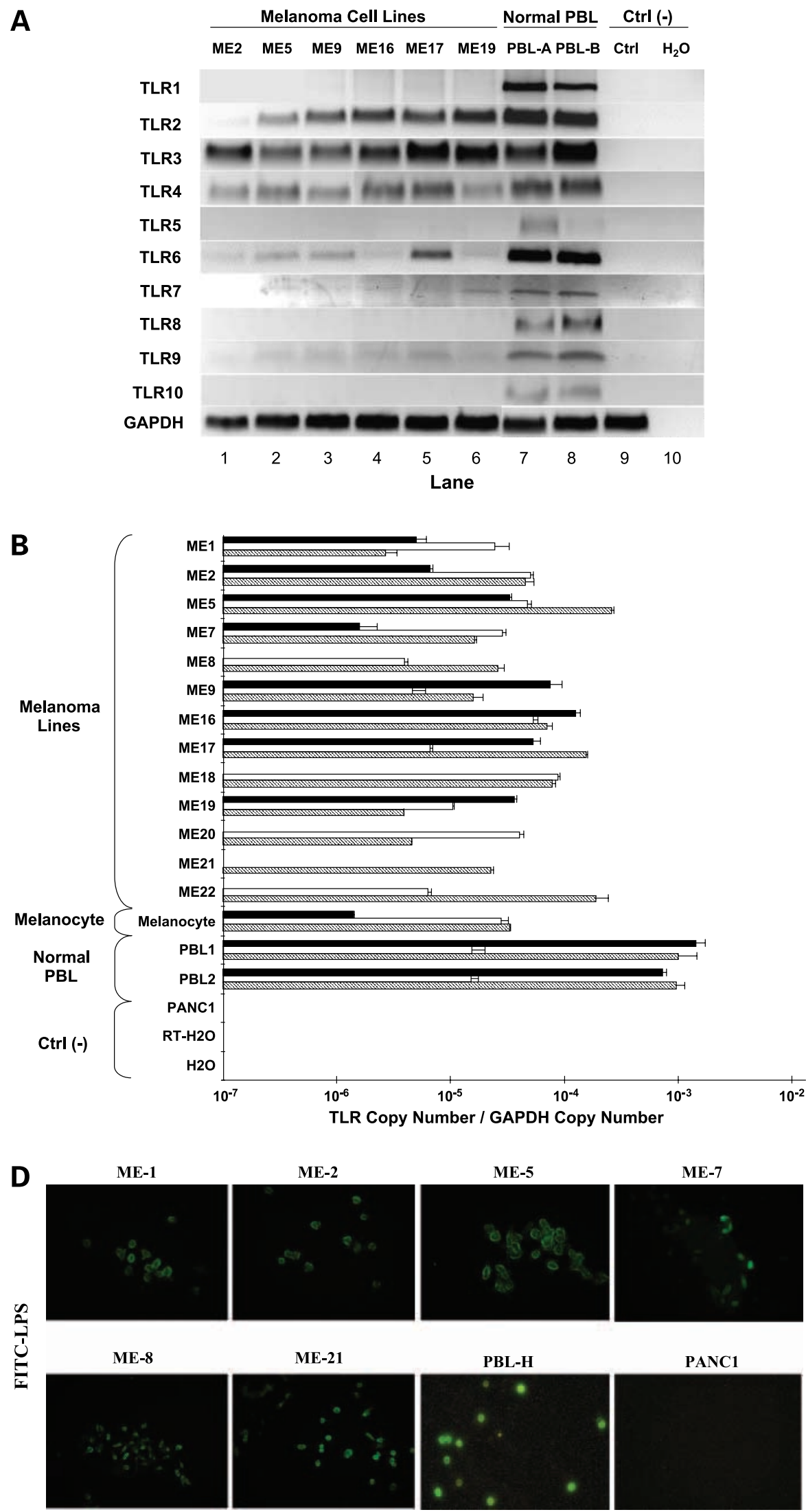
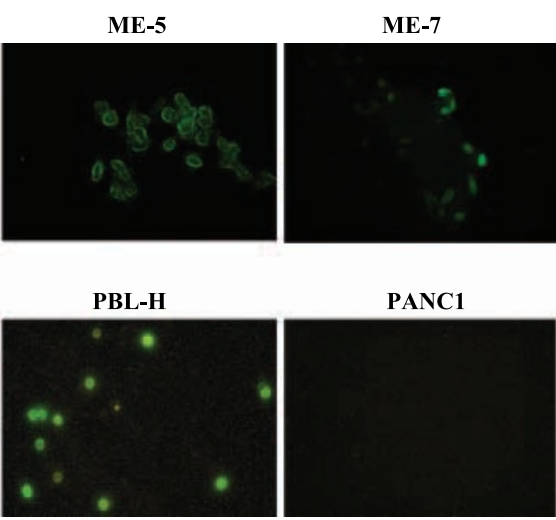

Figure 1. Expression of TLRs in human melanoma lines. A, expression of TLRs (TLR1 - TLR10) in six representative human melanoma lines and two normal donor PBLs was analyzed by RT-PCR and gel electrophoresis. Colon cancer cell line SW480 was used as a negative control (Ctrl). B, expression of TLRs in melanoma lines, melanocytes, and healthy donor PBLs was analyzed by qRTPCR. The $X$ axis is the copy number of each gene over the copy number of the housekeeping gene GAPDH. Small bars, SD. TLR2; $\square$, TLR3; 圈, TLR4. D, six melanoma cells were stained with FITC-LPS and visualized by fluorescence light microscopy. PBL from healthy individuals was used as a positive control, and PANC1 was used as a negative control. 

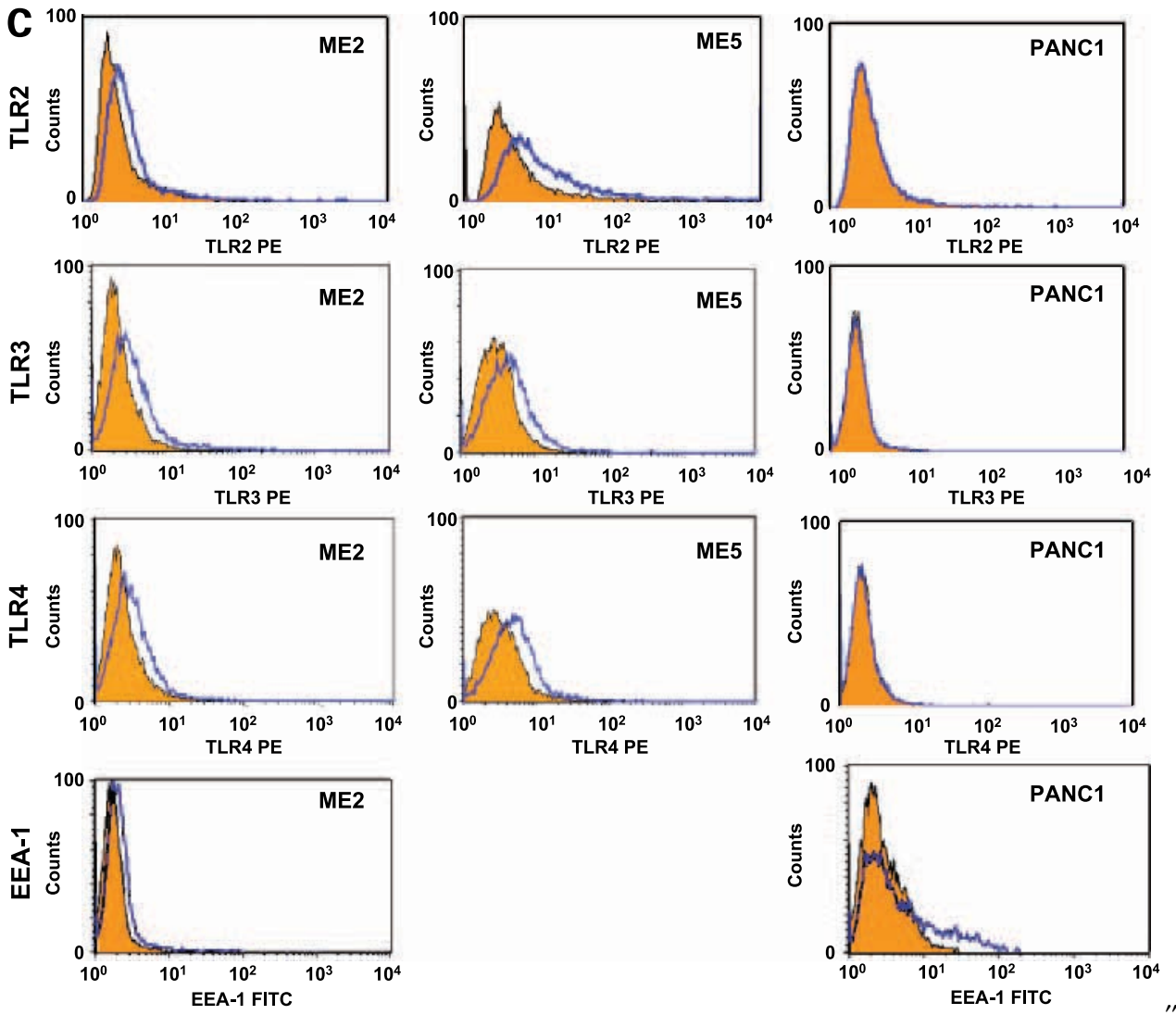

Figure 1 Continued. C, representative melanoma cell lines fluorescence-activated cell sorting analysis of TLR2, TLR3, TLR4, and early endosome antigen 1. Early endosome antigen 1 is endosome protein and a positive control of TLR3. PANC1 was a negative control. Left curve shaded area is the isotype control.
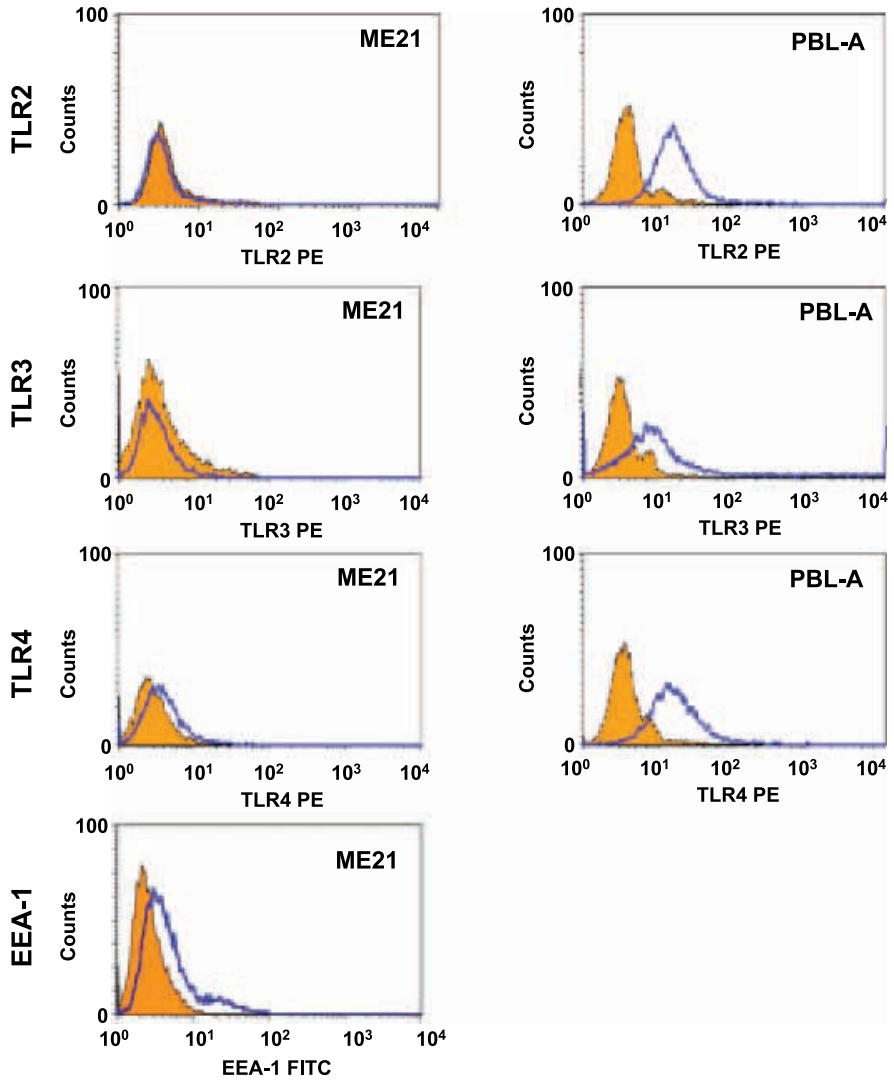
zymosan. Stimulation of cells with LPS induced $1.46 \times$ and $1.31 \times$ increase of TRIF expression, and $17.40 \times$ and $13.83 \times$ increase of MyD88 in ME2 and ME5 lines, respectively. Stimulation of cells with PIC also induced $1.31 \times$ and $1.45 \times$ increase of TRIF expression and $28.25 \times$ and $20.63 \times$ increase of MyD88 in ME2 and ME5, respectively.

As shown in Table 1, stimulation of melanoma cells with LPS increased expression of multiple proinflammatory cytokine. Stimulation with PIC enhanced tumor necrosis factor- $\alpha$ (TNF- $\alpha)$ expression. Stimulation with zymosan increased expression enhanced granulocyte colony-stimulating factor by $>8 \times$, and of interleukin-1 (IL-1), by $>2 \times$. Cyclooxygenase-2 (Cox-2) an inflammatory factor, was significantly up-regulated $>4 \times$ by all ligands.

These results strongly indicated that stimulation of TLR2, TLR3, or TLR4 on melanoma cells by their respective ligands activates signal transduction pathways similar to
TLR ligand activation on immune cells. After stimulation with their respective ligands, TLR and MyD88 were shown to be activated in melanoma cells; downstream signaling factors of the NF- $\kappa$ B and IRF families were significantly upregulated. The up-regulation of these genes was related to the up-regulation of specific proinflammatory cytokines and chemokines, as shown in Table 1.

\section{Cell Migration}

TLR activation is known to promote the migratory response of leukocytes (24); therefore, we assessed whether activation of TLR signaling can promote migration in melanoma cells. To show the functional response of melanoma cells to ligand binding of TLRs, the migration of melanoma lines ME2, ME5, and ME7 was assessed in the presence and absence of each of three TLR ligands (LPS, PIC, and zymosan). As shown in Fig. 5, LPS and PIC significantly increased migration in all the melanoma lines,

A
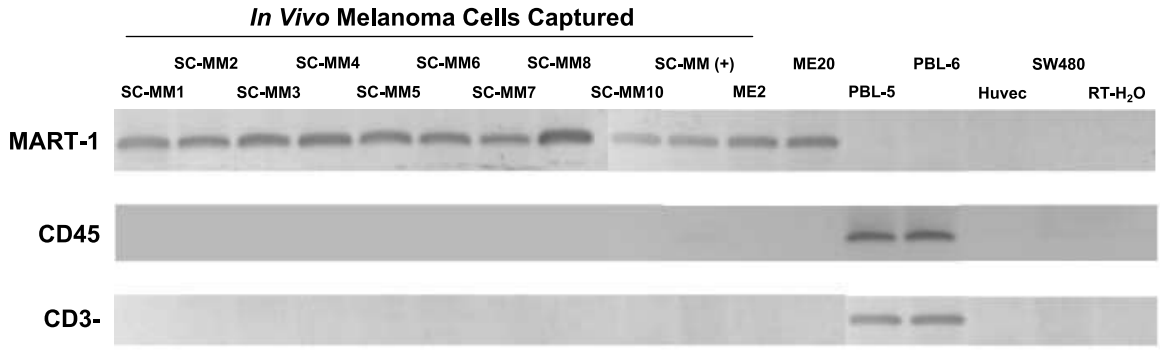

CK20

CD34

GAPDH
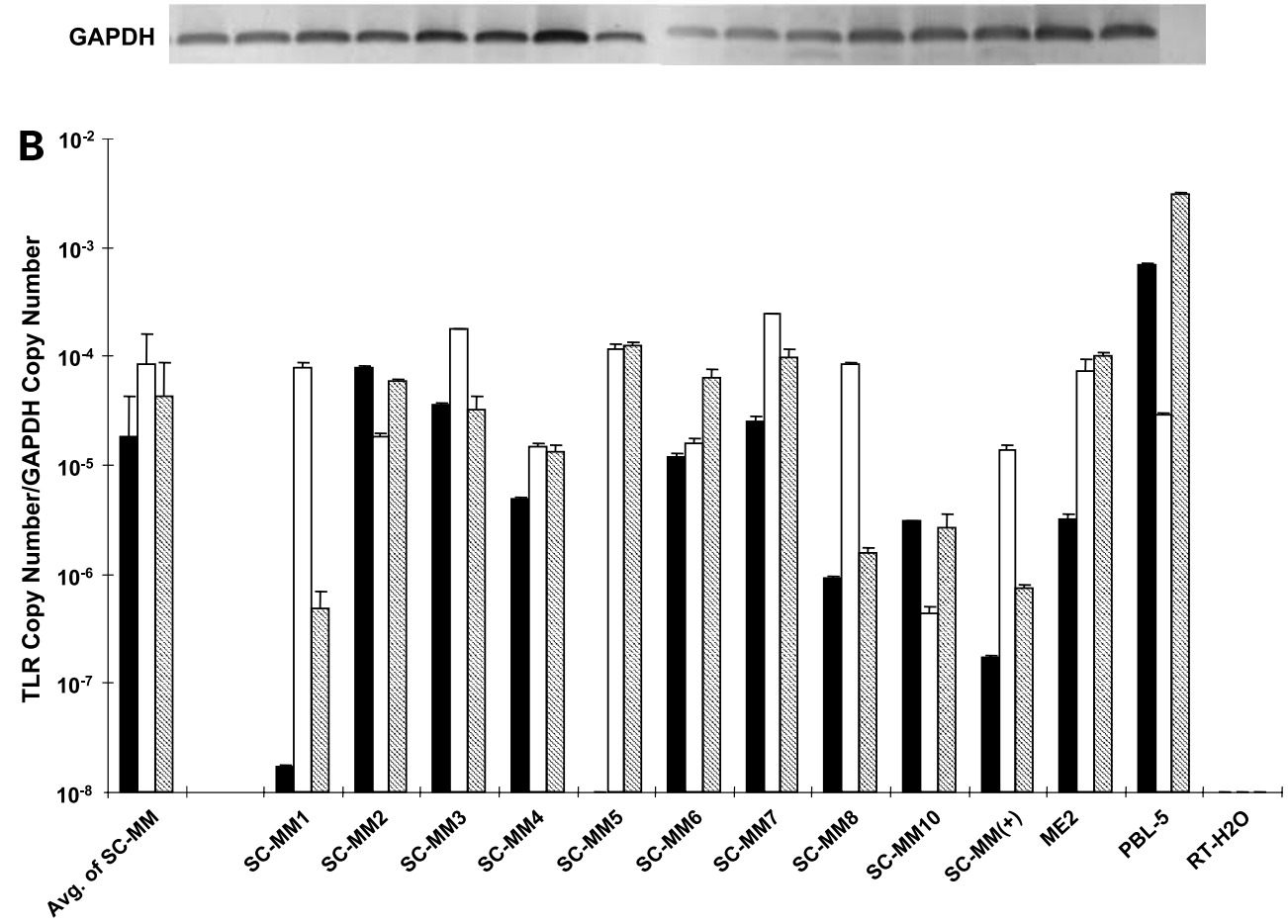

Figure 2. Expression of TLRs in isolated melanoma cells from tumor biopsy specimens. A, expression of MART-1, CD45, CD3- $\gamma$, cytokeratin 20, and CD34 in melanoma cells derived from 10 primary cutaneous melanoma was analyzed by RT-PCR. SC-MM is a positive control of primary melanoma cells. Melanoma lines (ME2 and ME20), normal donor PBLs (PBL1, PBL2), Huvec, and colon cancer line (SW480) were used as positive controls of each marker, respectively. B, expression of TLRs in isolated melanoma cells derived from biopsy specimens of melanomas was analyzed by qRT$\mathrm{PCR}$. $\mathrm{SC}-\mathrm{MM}(+)$ is a positive control of isolated melanoma cells, ME2 is a melanoma line, and PBL5 is from a healthy individual. The first set of columns on the left shows the average for the nine biopsy-derived cells. $Y$ axis is the gene copy number over the housekeeping gene GAPDH copy number. Small bars, SD. $\mathbf{0}, \mathrm{TLR} 2 ; \square$, TLR3; 원, TLR4. 


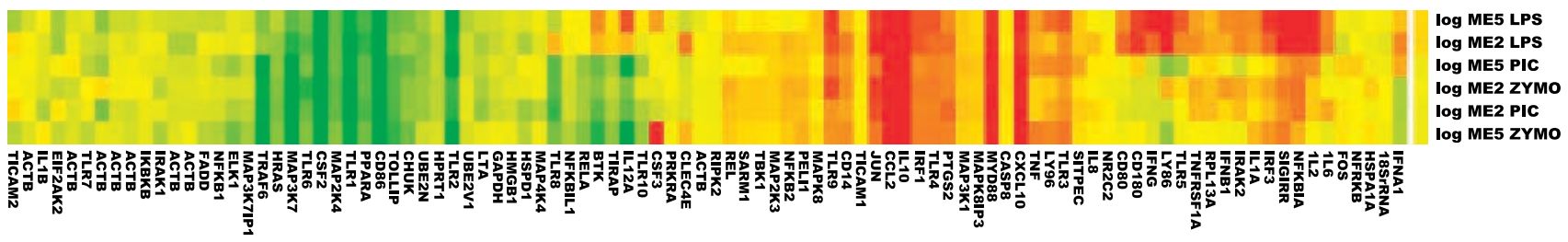

Figure 3. Heat map of quantitative PCR array analysis. Genes appear on the bottom of the heat map, and melanoma lines stimulated with ligand appear on the right side. Red, yellow, and green indicate higher, equivalent, and lower expression, respectively, in comparison with the expression in melanoma lines before stimulation.

whereas zymosan significantly increased migration in the ME5 cell line. The induction of cell migration after respective ligand-mediated activation of TLR2, TLR3, and TLR4 suggests that TLR-specific ligand activation can facilitate melanoma cell migration similar to that of leukocytes.

Melanoma TLR Activation by Activated PBL Supernatant

To determine if hematopoietic cells in the tumor microenvironment may activate TLR on melanoma cells, we assessed TLR2, TLR3, and TLR4 expression in ME1, ME2, ME5, and ME7 melanoma lines that had been cultured with supernatant from PHA-L-stimulated PBLs of several healthy donors. As shown in Fig. 6A, the mRNA expression of both TLR2 and TLR3 increased significantly in all four cell lines after stimulation with PBL supernatant. Expression of TLR4 increased significantly in three of the four melanoma lines. The expression of the MyD88 (adaptor molecule of TLR) was assessed and shown to significantly increase $1.8 \times, 2.6 \times, 3.2 \times$, and $4.0 \times$ after stimulation with PBL supernatant in melanoma lines ME1, ME2, ME5, and ME7, respectively, compared with supernatant from unstimulated PBLs. There was no significant difference in MyD88 mRNA copy number when comparing melanoma lines cultured with control medium and lines cultured with supernatant from unstimulated PBLs. These findings indicate that TLR expression on melanoma cells can be up-regulated and functionally activated through the release of soluble factors by stimulated PBL. This in vitro study may mimic actions of activated infiltrating lymphocytes in melanoma lesions.

Studies have shown that RNA can be released by tumor or normal cells and detected in blood $(25,26)$. To assess a potential factor from activated PBLs that may activate TLRs on melanoma cells, we focused particularly on TLR3. Purified RNA, which is a ligand of TLR3, was added individually to melanoma cells. Purified RNA from PBL (three healthy donors) or two melanoma lines was incubated with three different melanoma lines; TRIF mRNA expression was then assessed by qRT-PCR (Fig. 6B). The experiments showed that both PBL and melanoma RNA could activate TRIF expression by melanoma cells, particularly for ME5 and ME7. Responsiveness of melanoma cell lines varied. TLR3 expression analysis by qRT-PCR after RNA stimulation of PBL donor and melanoma cell lines also up-regulated
TLR3 expression by $20 \%$ to $98 \%$ (data not shown). This suggests that free RNA is a potential factor responsible for specific TLR activation.

\section{Discussion}

Our study has shown that TLR3 and TLR4 are strongly expressed on cells isolated from melanoma biopsies, and TLR2 is expressed in cell lines from cultured cells and cells isolated from melanoma biopsies. Other TLR family members were expressed, but less frequently and at a lower level. Melanocytes, keratinocytes, and langerhans cells comprise the epidermal barrier against exogenous pathogens and UV light. Activation of TLR on normal Langerhans cells and keratinocytes has been linked to the innate immune response of the skin to microbial pathogens $(27,28)$. Similarly, in an inflammatory, protective response to injury, sunburn, and infection of the skin, TLR activation on melanocytes may be a natural defense to recruit innate immune cells. TLR seem to be abnormally up-regulated in melanoma cells.

Chronic inflammation is a risk factor for the development and progression of cancer. Infiltration of tumors with specific T-cell subsets can be beneficial to control the tumor; however, overabundant innate immune cells and chronic inflammation can also relate to angiogenesis and poor prognosis (12). Innate immune cells, e.g., granulocytes, dendritic cells, macrophages, natural killer cells, and mast cells have TLR. Activation of TLR triggers a cascade of intracellular events, including innate immune responses through NF- $\kappa \mathrm{B}$-dependent and interferon regulating factor (IRF)-dependent signaling pathways. This is known to recruit and activate leukocytes to sites (29).

Until now, studies have indicated that immune cells produce cytokines and chemokines in the microenvironment of the tumor-promoting inflammation. However, we hypothesized that melanoma cells may also be involved in the production of cytokines and chemokines through activation of tumor cell TLR. When inflammation occurs in the skin microenvironment of melanoma tumors, innate immune responses are activated initially through TLR, often then leading to specific immunity. We believe this response may be beneficial initially to control melanoma tumor development; however, it may be a major detrimental factor to the host if it persists. 
Table 1. The expression profile of TLRs, its adaptor genes, effector genes, and TLR downstream signaling genes

\begin{tabular}{|c|c|c|c|c|c|}
\hline Ligands* & $\begin{array}{l}\text { Increase in } \\
\text { expression }^{+}\end{array}$ & TLR and TLR adaptor & TLR effector & $\begin{array}{c}\text { Proinflammatory } \\
\text { cytokines }\end{array}$ & $\begin{array}{c}\text { Proinflammatory } \\
\text { chemokines }\end{array}$ \\
\hline \multirow[t]{3}{*}{ LPS } & $>8 \times$ & TLR9, MyD88 & NF-кB1, IRF3 & & CCL2, CXCL10 \\
\hline & $>4 \times$ & TLR3, TLR4 & IRF1 & IL-6 & \\
\hline & $>2 \times$ & CD14 & & TNF- $\alpha$, IL-1, G-CSF & \\
\hline \multirow[t]{3}{*}{ PIC } & $>8 \times$ & MyD88 & & & CCL2, CXCL10 \\
\hline & $>4 \times$ & TLR3, TLR4, TLR9 & NF-кB1 & & \\
\hline & $>2 \times$ & CD14 & NF-кB2, IRF1 & TNF- $\alpha$ & \\
\hline \multirow[t]{3}{*}{ Zymosan } & $>8 \times$ & MyD88 & & G-CSF & CCL2, CXCL10 \\
\hline & $>4 \times$ & TLR3, TLR4, TLR9 & IRF1 & & \\
\hline & $>2 \times$ & CD14 & NF-кB1, NF-кB2, IRF3 & IL-1 & \\
\hline
\end{tabular}

NOTE: Overall summary of PCR array analysis of the most highly significant activated TLRs, its adaptor genes, effector genes, cytokine, and chemokine genes. Abbreviation: G-CSF, granulocyte colony-stimulating factor.

*Ligands of TLRs which stimulated melanoma cells. Concentration of ligands: LPS, $1 \mu \mathrm{g} / \mathrm{mL} ; \mathrm{PIC}, 100 \mu \mathrm{g} / \mathrm{mL}$; zymosan, $10 \mu \mathrm{g} / \mathrm{mL}$.

${ }^{\dagger}$ Increase is calculated as the expression in stimulated cells/nonstimulated. The average expression in ME2 and ME5 is given.

We identified high levels of TNF- $\alpha$, IL-1, IL-6, and granulocyte colony-stimulating factor (proinflammatory cytokines); CCL2 and CXCL10 (proinflammatory chemokines); IL-10 (inhibitory factor of tumor immunity); and cyclooxygenase-2 (inflammatory factor) in melanoma cells treated by specific TLR2, TLR3, and TLR4 ligands. TNF- $\alpha$ is one of the key cytokines mediating the inflammatory processes during melanoma development (30). TNF- $\alpha$ controls leukocytic infiltration in tumors through modulation of chemokines and their receptors. It is known that melanoma cells produce TNF- $\alpha$, but the mechanism of activation is unknown (31).Chronic production of endogenous TNF- $\alpha$ in the tumor microenvironment can enhance tumor progression by inducing other cytokines/chemokines involved in cancer progression, such as IL-6 and CCL2 (31). CCL2 recruits macrophages; T cells which accumulate in the tumor site can adversely affect the local immune response outcome (32). CXCL10 is a T-helper cell type 1-associated proinflammatory chemokine, which has the potential to recruit T-helper cell type 1-type $\mathrm{T}$ cells (33). The activation of both CCL2 and CXCL10 would be highly supportive in escalating inflammation and immunity in the melanoma lesion.

Cox-2 was significantly elevated in melanoma cells by TLR ligands. Cyclooxygenase- 2 can catalyze the conversion of arachidonic acid to prostaglandins. Elevated cyclooxygenase- 2 is associated with aggressive tumor phenotypes (34). Ligand activation of TLR enhanced IL-10 $(>8 \times)$ very significantly in melanoma cells. IL-10, a T-helper cell type 2 -type pleiotropic cytokine, can hinder a number of immune functions and suppress antitumor immunity. This provides a mechanism through which melanoma cells, activated by specific TLR ligands, can produce immune suppression factors. The induction of

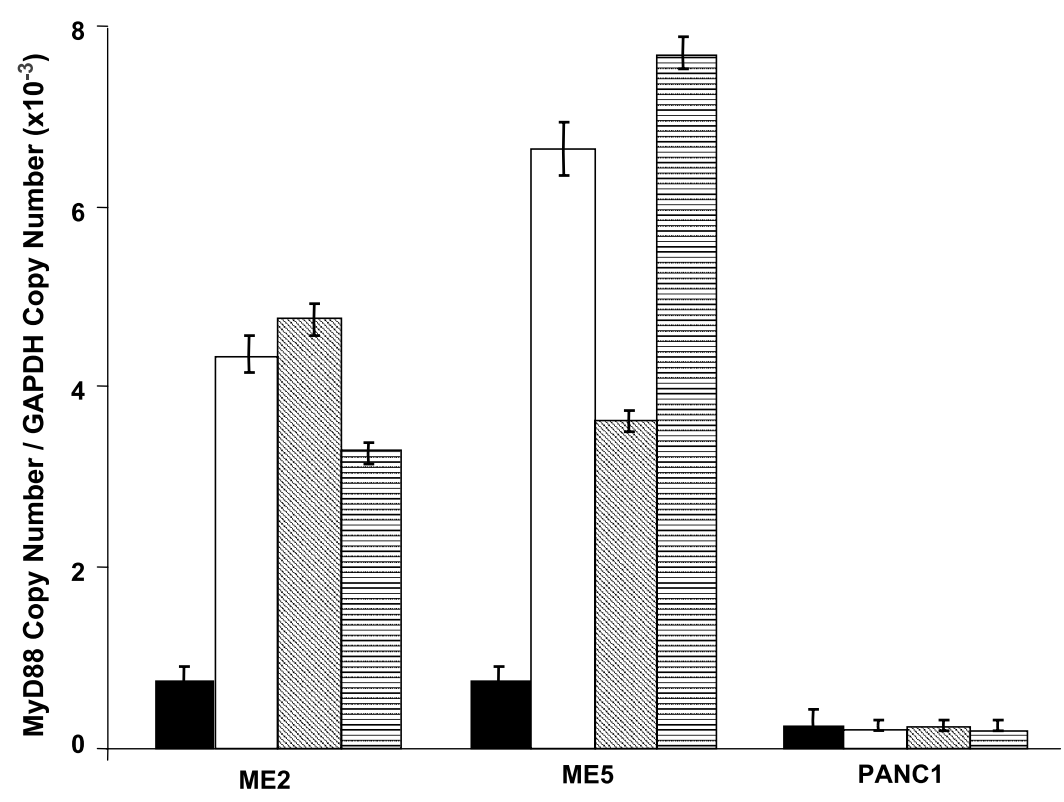

Figure 4. Expression of MyD88 after stimulation using TLR ligands. Expression of MyD88 in two melanoma lines and one negative control cell line (PANC1) was analyzed by qRT-PCR. Each cell line stimulated by LPS, PIC, or zymosan was compared with each unstimulated cancer line. The vertical axis is the copy number of MyD88 over the copy number of the housekeeping gene GAPDH. Small bars, SD. unstimulated; $\square$, LPS; 圈, PIC; 目, zymosan. 
Figure 5. Response to TLR ligands of three melanoma cells (ME2, ME5, and ME7) and one negative control cell line (PANC1) was assessed by a cell migration assay. The number of migrating cells in 10 randomly selected fields was counted after $24 \mathrm{~h}$ of incubation with and without ligands for TLR2, TLR3, and TLR4. One representative experiment of three is depicted. Small bars, SD. @, unstimulated; $\square$, ligand-stimulated cancer line.

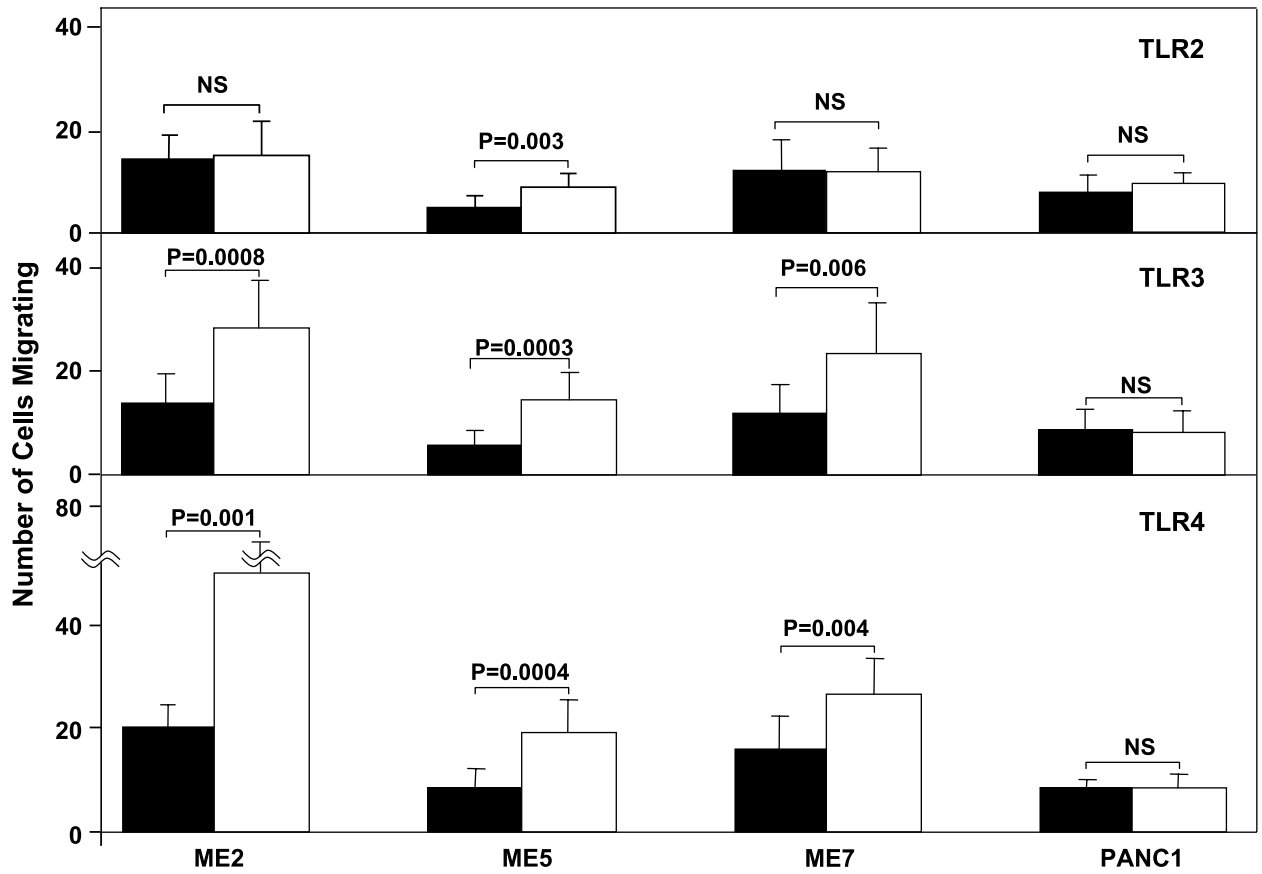

IL-10 in melanoma cells may facilitate tumor progression by inhibiting the generation of antitumor T-cell responses (35). IL-10 is known as a strong immunosuppression factor. This supports the role of tumor-related bioactive molecules in modifying the tumor microenvironment by dampening potential T-cell immune response, thus facilitating tumor progression. The role of IL-10 in melanoma-induced immune suppression is important and requires further studies.

We showed that MyD88, NF-кB1, NF-кB2, IRF1, and IRF3 were all significantly stimulated by activation of TLR2, TLR3, and TLR4 in melanoma cells. This signal transduction pathway mimics those found in hematopoietic cells. $\mathrm{NF}-\kappa \mathrm{B}$ plays a key role in regulating the immune response and controls many genes involved in inflammation, such as growth factors, cytokines, and chemokines. NF-кB, IRF1, and IRF3 downstream of MyD88 signal transduction pathway were significantly activated by respective TLR ligation. Studies have shown that activation of NF- $\kappa$ B also activates antiapoptotic proteins, thereby promoting tumor progression $(36,37)$. Activation of the MyD88 pathway can cause chemoresistance (7), a significant problem in treatment of systemic melanoma metastasis. NF- $\kappa B$ and IRF family members may play a significant role in regulating cytokine and chemokine production and recruiting immune cells in the tumor microenvironment.

Recently, a number of endogenous molecules have been reported to be ligands of TLR. For example, fibrinogen and heat shock protein 60, heat shock protein 70, gp96, and high mobility group box 1 protein may serve as ligands of TLR2 and/or TLR4 (38). Kariko et al. showed that TLR ligation with mRNA released from necrotic cells activates immune responses (39). Recent studies have shown RNA can be released by tumor cells and circulate in blood $(25,26)$. We speculated that TLRs on melanoma cells are activated by endogenous ligands within the tumor. In our study, surprisingly, the expression of TLR2, TLR3, TLR4, and MyD88 significantly increased when melanoma cells were cultured with supernatant from PHA-L-activated leukocytes. This supernatant likely includes potential agonists released from cells responsive to activated TLR-mediated signaling. The in vitro studies showed that incubation of RNA activates melanoma cells. This may be an important event, because elevated circulating RNA in the blood of cancer patients can be detected and correlated to poorer disease outcomes (26). The TLR3 response to RNA is likely due to RNA secondary structures, including doublestranded regions (39).

The activation of specific TLR by ligation has been suggested to activate adjacent ligands as an overall response in immune cells (40). We observed in our studies that specific TLR ligation activated expression of other TLR. This is the first demonstration that this event also occurs in nonimmune cells. Also, this suggests that TLR-ligand interactions on tumor cells are programmed to be very responsive to external changes in the tumor microenvironment and the TLR signal transduction pathways are wellintegrated.

In summary, our study has shown that TLR2, TLR3, and TLR4 were highly expressed in human melanoma in vivo and in vitro. Melanoma cells may be activated by endogenous ligands within the tumor; this activation stimulates cytokines and chemokines that may promote inflammation of the tumor microenvironment. TLR2, TLR3, and TLR4 ligation may also promote events of metastasis. We suggest that melanoma cells responding 
to TLR activation cause innate immune responses that may set the stage for an active inflammatory state favoring tumor promotion and suppression of host-specific immunity. TLR activation of tumor cells has been suggested to be a factor promoting tumor progression in carcinomas (41). We showed that TLR ligand activation in melanoma cells induced migration. Further studies are also needed to determine the role of TLR activation in supporting invasion and metastasis. Future studies will need to define the function of TLR on melanoma cells relative to in vivo host antitumor immunity. TLR and their signaling pathways may be potential therapeutic targets. Currently, there are several therapeutics targeting TLRs on leukocytes, as well as tumors (42), in phase I/phase II clinical trials in patients with different cancers, including melanoma.
A

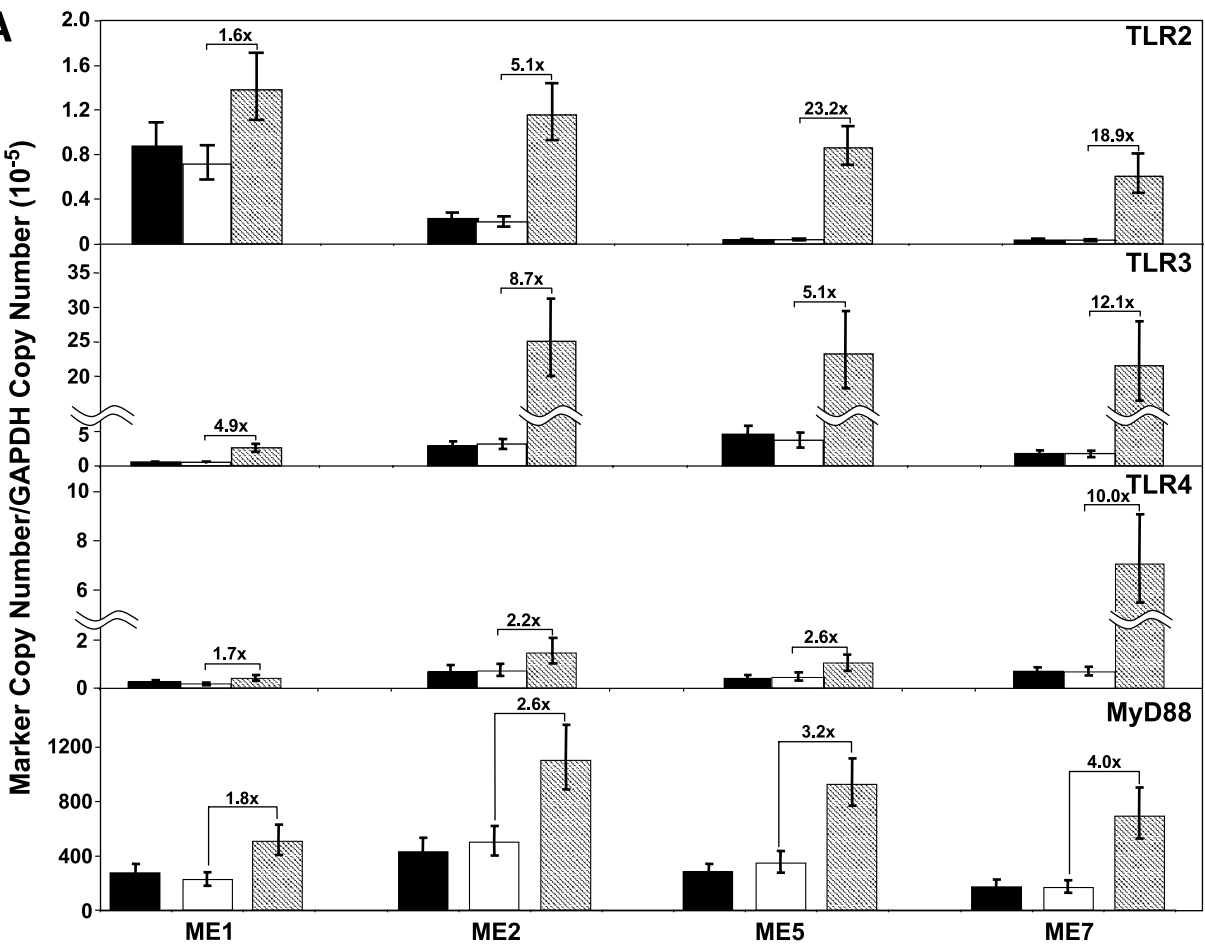

Figure 6. Melanoma line response to stimulated PBL supernatant and RNA. A, expression level of TLR2, TLR3, TLR4, and MyD88 in four melanoma lines (ME1, ME2, ME5, and ME7) cultured with supernatant of PBLs from four donors (PBL1, PBL2, PBL3, and PBL4) was analyzed by qRT-PCR. $\square$, melanoma cells cultured with a control medium; $\square$ melanoma cells cultured with super-

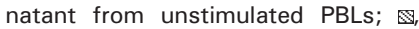
melanoma cells cultured with supernatant from PHA stimulated PBLs. Small bars, 95\% confidence intervals. The $Y$ axis is the copy number of each gene over the copy number of the housekeeping gene GAPDH. B, expression level (mean) of TRIF mRNA in three melanoma lines (ME1, ME5, and ME7) cultured with supernatant of PBLs (three donors) stimulated with PHA-L and $\square$ ME (two melanoma cell lines ME1 and ME5) analyzed by qRT-PCR. The $Y$ axis is the percentage of increase of TRIF mRNA expression in cells cultured with RNA compared with cells without RNA. Small bars, SD. *, actual mean increase of TRIF expression was $566 \pm 497 \%$ for ME7 line incubated with melanoma cell RNA. 


\section{Disclosure of Potential Conflicts of Interest}

The authors applied for patent ownership. No other potential conflicts of interest were disclosed.

\section{Acknowledgments}

We thank Gwen Berry and Linhda Nguyen for expert editorial assistance Alejandro Velasco for laboratory support, and Xing Ye for biostatistical support.

\section{References}

1. Medzhitov R, Preston-Hurlburt P, Janeway CA, Jr. A human homo logue of the Drosophila Toll protein signals activation of adaptive immunity. Nature 1997;388:394- 7.

2. Takeda K, Kaisho T, Akira S. Toll-like receptors. Annu Rev Immuno $2003 ; 21: 335-76$

3. Tsuji $S$, Matsumoto $M$, Takeuchi $O$, et al Maturation of human dendritic cells by cell wall skeleton of Mycobacterium bovis bacillus Calmette-Guerin: involvement of toll-like receptors. Infect Immun 2000 68:6883-90

4. Uehori J, Matsumoto M, Tsuji S, et al. Simultaneous blocking of human Toll-like receptors 2 and 4 suppresses myeloid dendritic cell activation induced by Mycobacterium bovis bacillus Calmette-Guerin peptidoglycan. Infect Immun 2003;71:4238-49.

5. Molteni M, Marabella D, Orlandi C, Rossetti C. Melanoma cell lines are responsive in vitro to lipopolysaccharide and express TLR-4. Cancer Lett $2006 ; 235: 75-83$

6. Morikawa T, Sugiyama A, Kume H, et al. Identification of Toll-like receptor 3 as a potential therapeutic target in clear cell renal cell carcinoma. Clin Cancer Res 2007;13:5703-9.

7. Kelly MG, Alvero AB, Chen $R$, et al. TLR-4 signaling promotes tumor growth and paclitaxel chemoresistance in ovarian cancer. Cancer Res 2006;66:3859- 68 .

8. Salaun B, Lebecque S, Matikainen S, Rimoldi D, Romero P. Toll-like receptor 3 expressed by melanoma cells as a target for therapy? Clin Cancer Res 2007;13:4565 - 74

9. Meyer $\mathrm{T}$, Stockfleth $\mathrm{E}$, Christophers $\mathrm{E}$. Immune response profiles in human skin. Br J Dermatol 2007;157 Suppl 2:1 - 7 .

10. Balkwill F, Mantovani A. Inflammation and cancer: back to Virchow? Lancet $2001 ; 357: 539-45$

11. Coussens LM, Werb Z. Inflammation and cancer. Nature 2002;420 $860-7$.

12. de Visser KE, Coussens LM. The interplay between innate and adaptive immunity regulates cancer development. Cancer Immuno Immunother 2005;54:1143 - 52.

13. Mantovani A. Cancer: inflammation by remote control. Nature 2005 435:752 - 3.

14. Mori $\mathrm{T}, \mathrm{Kim} \mathrm{J}$, Yamano $\mathrm{T}$, et al. Epigenetic up-regulation of $\mathrm{C}-\mathrm{C}$ chemokine receptor 7 and $\mathrm{C}-\mathrm{X}-\mathrm{C}$ chemokine receptor 4 expression in melanoma cells. Cancer Res 2005;65:1800-7

15. Sarantou T, Chi DD, Garrison DA, et al. Melanoma-associated antigens as messenger RNA detection markers for melanoma. Cancer Res 1997;57:1371-6.

16. Takeuchi H, Fujimoto A, Tanaka M, Yamano T, Hsueh E, Hoon DS. CCL21 chemokine regulates chemokine receptor CCR7 bearing malignant melanoma cells. Clin Cancer Res 2004;10:2351 - 8 .

17. Kuo CT, Hoon DS, Takeuchi $\mathrm{H}$, et al. Prediction of disease outcome in melanoma patients by molecular analysis of paraffin-embedded sentine lymph nodes. J Clin Oncol 2003;21:3566-72.

18. Koyanagi K, O’Day SJ, Gonzalez R, et al. Serial monitoring of circulating melanoma cells during neoadjuvant biochemotherapy for stage III melanoma: outcome prediction in a multicenter trial. J Clin Oncol 2005 23:8057-64.

19. Takeuchi $\mathrm{H}$, Morton $\mathrm{DL}$, Kuo $\mathrm{C}$, et al. Prognostic significance of molecular upstaging of paraffin-embedded sentinel lymph nodes in melanoma patients. J Clin Oncol 2004;22:2671-80
20. Goto $Y$, Matsuzaki $Y$, Kurihara S, et al. A new melanoma antigen fatty acid-binding protein 7 , involved in proliferation and invasion, is a potentia target for immunotherapy and molecular target therapy. Cancer Res 2006; $66: 4443-9$

21. Jiang $Z$, Zamanian-Daryoush $M$, Nie $H$, Silva $A M$, Williams $B R$ Li X. Poly(I-C)-induced Toll-like receptor 3 (TLR3)-mediated activation of $\mathrm{NF} \kappa \mathrm{B}$ and MAP kinase is through an interleukin-1 receptor-associated kinase (IRAK)-independent pathway employing the signaling components TLR3 - 6-TAK1 - 2-PKR. J Biol Chem 2003;278:16713-9.

22. Campoli MR, Chang CC, Kageshita T, Wang X, McCarthy JB, Ferrone S. Human high molecular weight-melanoma-associated antigen (HMW-MAA): a melanoma cell surface chondroitin sulfate proteoglycan (MSCP) with biological and clinical significance. Crit Rev Immunol 2004; $24: 267-96$

23. Dunne A, O'Neill LA. Adaptor usage and Toll-like receptor signaling specificity. FEBS Lett 2005;579:3330 - 5 .

24. Fan J, Malik AB. Toll-like receptor-4 (TLR4) signaling augments chemokine-induced neutrophil migration by modulating cell surface expression of chemokine receptors. Nat Med 2003;9:315-21.

25. Kopreski MS, Benko FA, Kwak LW, Gocke CD. Detection of tumo messenger RNA in the serum of patients with malignant melanoma. Clin Cancer Res 1999;5:1961 - 5

26. Ng EK, Tsui NB, Lam NY, et al. Presence of filterable and nonfilterable mRNA in the plasma of cancer patients and healthy individuals. Clin Chem 2002;48:1212- 7

27. Flacher V, Bouschbacher M, Verronese $E$, et al. Human langerhans cells express a specific TLR profile and differentially respond to viruses and Gram-positive bacteria. J Immunol 2006;177:7959-67.

28. Kollisch G, Kalali BN, Voelcker V, et al. Various members of the Tolllike receptor family contribute to the innate immune response of human epidermal keratinocytes. Immunology 2005;114:531-41.

29. Akira S, Takeda K. Toll-like receptor signalling. Nat Rev Immuno 2004; $4: 499-511$

30. Szlosarek PW, Balkwill FR. Tumour necrosis factor $\alpha$ : a potentia target for the therapy of solid tumours. Lancet Oncol 2003;4:565-73.

31. Balkwill F. Tumor necrosis factor or tumor promoting factor? Cytokine Growth Factor Rev 2002;13:135 - 41.

32. Pollard JW. Tumour-educated macrophages promote tumour progression and metastasis. Nat Rev Cancer 2004;4:71 - 8

33. Brightling $C E$, Ammit $A J$, Kaur $D$, et al. The $C X C L 10 / C X C R 3$ axis mediates human lung mast cell migration to asthmatic airway smooth muscle. Am J Respir Crit Care Med 2005;171:1103 - 8

34. de Maat MF, van de Velde CJ, Umetani N, et al. Epigenetic silencing of cyclooxygenase-2 affects clinical outcome in gastric cancer. J Clin Oncol 2007;25:4887-94.

35. Steinbrink K, Graulich E, Kubsch S, Knop J, Enk AH. CD4(+) and $\mathrm{CD} 8(+)$ anergic $T$ cells induced by interleukin-10-treated human dendritic cells display antigen-specific suppressor activity. Blood 2002;99: 2468 - 76 .

36. Greten FR, Eckmann L, Greten TF, et al. IKK $\beta$ links inflammation and tumorigenesis in a mouse model of colitis-associated cancer. Cell 2004 118:285- 96 .

37. Pikarsky E, Porat RM, Stein I, et al. NF-kB functions as tumour promoter in inflammation-associated cancer. Nature 2004:431: $461-6$.

38. Tsan MF. Toll-like receptors, inflammation and cancer. Semin Cance Biol 2006;16:32-7

39. Kariko K, Ni H, Capodici J, Lamphier M, Weissman D. mRNA is an endogenous ligand for Toll-like receptor 3. J Biol Chem 2004;279: $12542-50$

40. Trinchieri G, Sher A. Cooperation of Toll-like receptor signals in innate immune defence. Nat Rev Immunol 2007;7:179 - 90.

41. Huang $B$, Zhao J, Unkeless JC, Feng ZH, Xiong $H$. TLR signaling by tumor and immune cells: a double-edged sword. Oncogene 2008;27: $218-24$

42. Parkinson $T$. The future of toll-like receptor therapeutics. Curr Opin Mol Ther 2008; 10:21-31. 